\title{
The impact of the Bologna Process on academic staff in Ukraine
}

\author{
by \\ Marta A. Shaw, David W. Chapman and Nataliya L. Rumyantseva, \\ University of Minnesota, United States \\ and University of Southampton, United Kingdom
}

Academic staff in Ukraine face a convergence of institutional and professional pressures precipitated by a national economic crisis, projected declines in enrolment and dramatic changes to institutional procedures as institutions implement the Bologna Process. This article examines the extent to which these pressures are reshaping the way academic staff engage in their day-to-day work, their careers and their role in their university. Findings indicate that faculty are caught in a confluence of conflicting demands that elicits adaptive coping strategies and threatens to undermine national efforts to modernise Ukraine's higher education system. 


\title{
L'impact du processus de Bologne sur le personnel universitaire en Ukraine
}

\author{
par \\ Marta A. Shaw, David W. Chapman et Nataliya L. Rumyantseva, \\ Université du Minnesota, États-Unis \\ et Université de Southampton, Royaume-Uni
}

Le personnel universitaire en Ukraine est confronté à la convergence des pressions institutionnelles et professionnelles générées par une crise économique nationale, des baisses d'inscriptions prévues et des changements conséquents dans les procédures institutionnelles des établissements supérieurs découlant de la mise en œuvre du processus de Bologne. Cet article examine dans quelle mesure ces pressions modifient la carrière $d u$ personnel académique ukrainien, leur investissement au quotidien et leur rôle dans la recherche universitaire et l'éducation. Des résultats indiquent que les universités ukrainiennes se situent au confluent de demandes contradictoires qui suscitent des stratégies d'adaptation et qu'elles menacent de miner les efforts nationaux pour moderniser le système de l'enseignement supérieur en Ukraine. 


\section{Introduction}

Over the last two decades, higher education systems in Eastern Europe have been navigating through an era of rapid transformation. Expanding higher education and improving its quality have risen to the top of national priorities as governments embrace the notion that higher education is a key component of their efforts toward economic and social development (Chapman, 2009). However, the rapid expansion of higher education and efforts to align it with Western European standards have often come at a cost, and sometimes with a twist. In few places is this truer than in Ukraine.

Since the turn of the century, higher education in Ukraine has experienced explosive enrolments. Between 2000-09, tertiary enrolments increased by about 185\% (UNESCO, 2010a). The percentage of the eligible age group enrolled in university studies grew from 47\% in 1999 to $79 \%$ in 2008 (UNESCO, 2010b), transforming the system into one of nearly universal access. The country has absorbed this growth both through expanding public higher education and by encouraging the development of private higher education options. As in other Eastern European countries, however, the expansion of access has often been accompanied by concerns about insufficient funding and declining quality (Kovtun and Stick, 2009).

In 2005, in an effort to raise the international legitimacy of its higher education system, Ukraine joined the Bologna Process. By doing so, it committed to an international effort to harmonise higher education that involved redesigning the curriculum, shifting to a three-cycle degree structure and submitting to cross-national mechanisms of quality assurance (Clement et al., 2004; Kremen and Nikolajenko, 2006). Recent reports suggest that the financial austerity facing Ukrainian higher education, coupled with the demands of implementing the Bologna Process, have put great pressure on both institutions and individual academic staff (Kovtun and Stick, 2009).

Policy options available to governments and higher education leaders centre to a large extent on how they mobilise, deploy and manage academic staff. ${ }^{1}$ Given that they are responsible for teaching courses and conducting research, faculty largely define the character, quality, productivity and relevance of each institution and of the higher education system as a whole (Chapman, 2009). Indeed, college and university faculty are the gatekeepers of higher education reform. Their attitudes and responses are crucial in 
determining the odds of successful reform and the modernisation of higher education.

Following its adoption of the Bologna Process, Ukraine provides a particularly interesting national context for examining how faculty in a postcommunist nation construct their careers at a time of rapid change. This study examines the extent to which the convergence of challenges currently faced by higher education institutions there is reshaping the way academic staff view their careers and professional roles. Our findings have wide relevance given the number of countries now seeking to align their higher education systems with international standards, creating new pressures for academic staff (Zgaga, 2006; Salmi, 2009).

\section{Conceptual framework}

Observers of higher education reform point out that during times of transition and reform, not all components of a higher education system embrace change at the same rate, neither do all actors necessarily agree on the shape of the new structures toward which they are moving (Chapman and Austin, 2002). Several authors offer theoretical models for thinking about how organisations and individuals respond to the vortex of pressures created in situations where elements of a larger reform process move forward at different rates. This study draws on Weaver's (2008) work in organisational sociology to highlight the key dynamics which emerge in a time of transformation. It also points to Bateson's (1972) contribution to the psychology of communications as a lens to examine how those dynamics impact individual faculty in the Ukrainian system.

Weaver (2008), building on earlier work by Pfeffer and Salancik (1978) and Brunsson (1989), argues that social institutions are dependent on externally conferred legitimacy, funding and demand for services. To receive funding and public support, they need to be responsive to public agendas. Yet social institutions also have their own informal structures, values and norms that may be different from those in the external culture. In some cases, conflicts arise between these societal goals and institutional objectives. We posit that this may be the case in the public university sector in Ukraine, where faculty are located at the intersection of a changing public agenda and the informal structures of the public university. The introduction of the Bologna Process was one of numerous shifts in European higher education policy over the last two decades, and it occurred at a time of fiscal austerity and decreasing enrolments. The public agenda of integration and harmonisation presented universities with the difficult challenge of navigating the gap between the government's new goals and their traditional goals, as reflected in the institutional structure. 
According to Weaver (2008), in response to tension generated by multiple expectations, a common coping strategy for an institution is to adopt reform goals and introduce structural changes in order to signal conformity to environmental expectations, while at the same time pursuing a different internal course of action. Caught in a squeeze of conflicting expectations, organisations "decouple". They build gaps between those activities that are externally demanded, on the one hand, and those that flow out of internal structures and culture on the other (Weaver, 2008, p. 5).

Eastern European sociologists have often noted that such discrepancies between external and internal actions are particularly ingrained in postcommunist societies (Sztompka, 2005). Fake and hidden activities served as coping strategies for both individuals and institutions to deal with the unrealistic demands of a centrally planned economy (Lutyński, 1990) and they have persisted as a strategy for navigating the turmoil of the post-communist era (Tyszka, 2009). Weaver's framework appeared particularly relevant in the context of this study, in light of the fact that scholars working in Eastern Europe have often observed a dissonance between the rhetoric and the reality of reforms since the post-communist transition (Marga, 1997). We posit that in the Ukrainian context, the process of decoupling can be framed as a series of contradictions that may lead academic staff to give lip-service to the symbolic goals needed to placate the environment, but in fact operate within an informal structure that determines how the work actually gets done (Weaver 2008, p. 5).

The dynamics Weaver discusses at the organisational level have a counterpart at the level of individuals. For academic staff, the effort of trying to satisfy multiple demands on their time can be framed as what Bateson (1972) calls a "double bind". While contradictory messages are common in interpersonal relationships, a double bind occurs when it is vital for the addressee to distinguish what kind of message is being transmitted, but conflicting communications are perpetually locked in ambiguity. Bateson suggests that for a double bind to occur, an individual must be in a significant relationship with an authority which issues contradictory statements or demands; these demands can be construed as mutually incompatible and the individual is incapable of addressing the situation or discussing it for the purpose of clarification. A double bind is most likely to arise in settings involving unequal power relations and limited personal autonomy. Since faculty and university authorities operate within an employment relationship and the higher education sector in Ukraine is rife with pressures and uncertainties, we posit that the concept of a double bind provides insight into the individual responses of academic staff. 


\section{Context}

\section{Higher education in Ukraine}

The legal framework that sets the organisational and financial basis for higher education in Ukraine is based on modern principles of merit-based access, as well as the targets of raising the levels of achievement and the quality of academic research (Ukrainian parliament, 2002). Nonetheless, the internal structure of the system is still highly centralised. As in many other post-Soviet nations, the Ministry of Education and Science has considerable control over how higher education institutions are run; as a result, Ukrainian universities are characterised by limited autonomy at all levels.

Government funding for higher education institutions is allocated in a manner that leaves them with little control over their budgets (Anon, 2009). ${ }^{2}$ Centralised control also applies to the universities' instructional programmes, the composition of their governance bodies and their organisational structures.

While universities operate within a fairly tight policy environment, they have some autonomy when identifying study programmes, recruiting staff, delivering additional educational services, developing research programmes, managing international collaboration and the use of institutional facilities. The question of individual academic autonomy is a little more delicate. Universities' internal structures tend to operate as steep hierarchies. Rectors hold a considerable amount of power (Kremen and Nikolajenko, 2006) and organisational actors share the assumption that decisions are made at the top. In this type of hierarchy, those lower down the organisational ladder see themselves as doers whose role is to implement decisions made further up the chain (Savage, 1990; Chapman et al., 2009).

Limited autonomy and a steep power ladder create a fertile ground for the emergence of double binds (Bateson, 1972). Without the power to confront the dilemmas communicated at higher levels, individuals and institutions are more likely to find themselves locked in ambiguity over perceived expectations.

\section{Context of the study}

This study was undertaken at a large university located outside the capital city, Kiev, that had recently undergone an external evaluation. The institution was selected on the basis of its accreditation as a national university and its location. The university offers a full range of degrees (Bachelor's, Master's, Candidate of Science and Doctor of Science) and is held in high academic regard. It has a student population of about 30000 and it is 
ranked in the top three public universities in its specialisation and in the top three higher education institutions in its region (Anon, 2009).

The senior management team consists of the rector and several vicerectors. It reports to the academic board, the university's top decision-making body which has the ultimate decision-making powers on a wide range of issues, ranging from broad strategic decisions to individual financial assistance and scholarships. In parallel, there is a similar top-heavy distribution of power between the faculties and departments (Anon, 2009). The curriculum is largely determined by the state, which leaves little space for innovation. While some faculty members are experimenting with newer pedagogical methods, instruction is, for the most part, delivered through lectures, with compulsory class attendance.

The complexity of organisational structure poses a challenge to the university's efforts to adjust to the changing environment. It is organised into nearly 70 departments in several branch campuses. In some cases, faculties appear to offer similar and overlapping coursework and programmes (Anon, 2009). With so many units, efforts to orchestrate a move in the same direction have been complicated as faculties, departments and individual academic staff members have adjusted at different rates to the new enrolment patterns, fiscal conditions and changing instructional priorities. This has led to misalignments among programmes and confusion about priorities.

The uncertainty and confusion arising from institutional change implemented through cumbersome channels in the organisational structure further contribute to the emergence of double binds, which directly affect faculty members. The diversity of responses at various levels of the hierarchy increases the odds that they receive messages that may, on occasion, contradict one another. The likelihood of double binds increases with the environmental challenges discussed below, which add to sources of pressure on the institution.

\section{A convergence of challenges}

The study revealed that the university is in the middle of a challenging transition period, created by the convergence of four factors.

1. Enrolment declines. Demographic shifts have had a dramatic effect on the university and its funding. After a period of explosive enrolment growth, it is facing the prospect of sharp declines in student admissions. In the early 1990s, the birth rate was low, resulting in a drop in the size of current college-age cohorts. The situation may be compounded in the future by a government plan (still under discussion) to increase the duration of basic education by either one or two years as of 2012, effectively eliminating secondary school graduations for those extension years. This would cut the 
flow of secondary graduates, seriously deplete the university's student intake during that time and, consequently, further reduce its tuition income.

2. Fiscal austerity. Since the university's budget is heavily tuition-dependent, the imminent enrolment declines will have grave financial consequences for the institution. One-third of the university's annual budget comes from government funding and two-thirds are self-generated, primarily from student tuition. As it is, Ukraine has been severely hit by the global economic crisis. This has resulted in greater problems for students in raising tuition fees and for the university in securing research funds from the government and other outside sources. Financial austerity has introduced uncertainty for academic staff, since they are hired on shortterm contracts and their job security is heavily contingent on the fiscal situation of the institution.

3. Implications of Bologna. When Ukraine embraced the Bologna reforms, the university entered a period of radical change in the educational process. It involved changes in the design of the curriculum, the academic calendar and student grading procedures, despite the fact that the institution was already in a difficult financial position. One of the outcomes of this change is that academic staff were expected to shift from teacher-oriented to student-centred instruction and to respond to a greater emphasis on research. The national and institutional commitment to comply with the Bologna goals adds complexity to the working lives of faculty and administrators. Yet, despite the pressure to embrace the Bologna-induced changes, there has been no systematic instructional redesign effort or real support for staff to implement these changes and the results seem patchy to external observers (Anon, 2009).

4. Push for research. In an effort to achieve greater national and international recognition, the university is trying to shift from being a primarily teachingoriented institution to one which focuses on research. Consequently, while the university has been a teaching-oriented culture, academic staff are now coming under considerable pressure to conduct research. The university has taken several steps to develop applied research tailored to the needs of the region and its enterprises.

\section{Methodology}

We selected a purposeful sample of academic respondents and over a two-week period in May 2010, we conducted interviews with 32 academic staff and 7 senior administrators. The sample had a good gender balance and approximately equal numbers of those who entered university before and after Ukraine's independence in 1991. The sample consisted of comparable 
numbers of academic staff from all main programme areas and all academic ranks were represented. The seven senior-level administrators were either deans or university-level administrators. The interviewees' characteristics are summarised in Table 1.

Table 1. Distribution of participants by age, gender, and academic rank

\begin{tabular}{lcc|cc}
\hline \multirow{2}{*}{ Rank } & $\begin{array}{c}\text { Entered university after independence } \\
\text { (37 years old or younger) }\end{array}$ & $\begin{array}{c}\text { Entered university before independence } \\
\text { (38 years old or older) }\end{array}$ & Female \\
\cline { 2 - 5 } & Male & Female & 6 & 0 \\
\hline Senior Administrator & 1 & 0 & 1 & 4 \\
Department head & 1 & 0 & 2 & 4 \\
Professor & 3 & 1 & 1 & 4 \\
Lecturer & 3 & 8 & 10 & 12 \\
TOTAL & 8 & 9 & Male & \\
\hline
\end{tabular}

Source: Marta A. Shaw, David W. Chapman and Nataliya L. Rumyantseva (2011), "Organizational Culture in the Adoption of the Bologna Process: A Study of Academic Staff at a Ukrainian University", Studies in Higher Education, published online 26 September 2011, http://dx.doi.org/10.1080/ 03075079.2011.614336.

Each interview lasted approximately one hour with an hour of buffer time between interviews to allow for continuation if the interviewee wished to extend the discussion. The interviews were conducted in Ukrainian, Russian or English, depending on the participant's preference.

The protocol for the semi-structured interviews was designed to collect information on interviewees' beliefs related to the nature of their work, their perceptions of environmental and institutional change, professional accountability, work motivation, and career and job satisfaction (Table 2). Interviews were recorded and contemporaneous notes were taken. Content analysis of interviews was conducted in the original languages in order to identify recurrent themes as well as the frequency and intensity with which respondents held those views.

\section{Findings}

Findings indicate that academic staff in Ukraine are caught in a trap of multiple and sometimes irreconcilable demands, driven in large part by the interaction of fiscal pressure on the university and the national commitment to raise the quality of its higher education system. Content analysis indicated three major cross-cutting themes emerging from the data. Each is best understood as a dilemma faced by academic staff that contributes to generate a double bind. 
Table 2. Faculty beliefs about their professional work

\begin{tabular}{|c|c|c|}
\hline & Frequency & Per cent \\
\hline \multicolumn{3}{|l|}{ Sources of job motivation } \\
\hline Love of teaching & 30 & $77 \%$ \\
\hline Stability of employment & 21 & $54 \%$ \\
\hline Prestige & 17 & $43 \%$ \\
\hline Limited options outside university & 15 & $38 \%$ \\
\hline Social protection and security & 14 & $36 \%$ \\
\hline Community and friendship & 13 & $33 \%$ \\
\hline Flexibility & 10 & $26 \%$ \\
\hline Proximity to family & 6 & $15 \%$ \\
\hline Love of research & 6 & $15 \%$ \\
\hline Not to be bored & 3 & $7 \%$ \\
\hline \multicolumn{3}{|l|}{ Sources of job satisfaction } \\
\hline Working with students & 29 & $74 \%$ \\
\hline Always doing something new & 17 & $43 \%$ \\
\hline Ability to travel & 5 & $13 \%$ \\
\hline Research & 4 & $10 \%$ \\
\hline \multicolumn{3}{|l|}{ Sources of job frustration } \\
\hline Insufficient salaries & 29 & $74 \%$ \\
\hline Lack of time for personal life & 20 & $51 \%$ \\
\hline Lack of time for research & 19 & $49 \%$ \\
\hline Too much paperwork and administrative work & 18 & $46 \%$ \\
\hline Unmotivated students & 10 & $26 \%$ \\
\hline Not getting paid to do administrative work & 7 & $18 \%$ \\
\hline \multicolumn{3}{|l|}{ Beliefs about salaries } \\
\hline My salary is not sufficient & 28 & $72 \%$ \\
\hline It is impossible to live on my salary alone & 19 & $49 \%$ \\
\hline My income is supplemented from other sources & 33 & $85 \%$ \\
\hline \multicolumn{3}{|l|}{ Changing nature of demands } \\
\hline Bologna process creates a lot of new pressures & 29 & $74 \%$ \\
\hline We are expected to do more research & 32 & $82 \%$ \\
\hline We are expected to teach in a more student-centred fashion & 31 & $79 \%$ \\
\hline We are expected to do more paperwork and administrative work & 23 & $59 \%$ \\
\hline \multicolumn{3}{|l|}{ Beliefs related to research } \\
\hline I experience (or exert) a lot of pressure to do research & 29 & $74 \%$ \\
\hline Research pressure has increased since Bologna & 33 & $85 \%$ \\
\hline My teaching load is too large to do good research & 21 & $54 \%$ \\
\hline The university does not support me sufficiently to do research & 17 & $44 \%$ \\
\hline \multicolumn{3}{|l|}{ Beliefs about job security } \\
\hline My job security depends on research & 37 & $95 \%$ \\
\hline $\begin{array}{l}\text { People who don't grow professionally don't have their contracts } \\
\text { prolonged }\end{array}$ & 24 & $61 \%$ \\
\hline Getting a doctoral degree brings greater job security & 23 & $59 \%$ \\
\hline Contracts are very short & 18 & $46 \%$ \\
\hline The university is very concerned with profitability & 16 & $41 \%$ \\
\hline My colleagues are concerned about their jobs & 12 & $31 \%$ \\
\hline
\end{tabular}

Source: Marta A. Shaw, David W. Chapman and Nataliya L. Rumyantseva (2011), "Organizational Culture in the Adoption of the Bologna Process: A Study of Academic Staff at a Ukrainian University", Studies in Higher Education, published online 26 September 2011, http://dx.doi.org/10.1080/03075079.2011.614336. 


\section{Faculty are expected to do more research, but their salaries are based on their teaching loads.}

Those interviewed for this study reported a significant increase in the pressure to conduct research since the country joined the European Higher Education Area. A large majority (74\%) of participants claimed that they either exert or experience a great deal of pressure to conduct research and $85 \%$ attributed the increased pressure to the adoption of the Bologna Process. They also stressed that research is not remunerated and they find it difficult to reconcile this fact with the academic workload, determined by the Ministry of Education and Science, that forms the basis of their salaries.

Workload is based on a standard formula that specifies an expectation for faculty to devote between 750 and 900 hours per year to instructional activities (course preparation, teaching, grading, advising), depending on their position and academic rank. Overall, interviewees estimated that they spend from five to seven hours a day interacting with students. They saw this as a heavy workload, and over half described it as a source of frustration. Faculty who entered university after Ukraine's independence, especially those familiar with university teaching loads common in other countries, were the most vocal in their criticism of the instructional time required of them. One faculty member observed:

We have to teach an average of four courses each semester. It's impossible to be an expert in all of these things - but if we taught less, we wouldn't have enough teaching time to receive a salary.

Their views found sympathy among some university administrators. In the words of one:

Nine hundred hours of contact time? In Europe, it's half that.

While a heavy workload and strong pressure to publish would perhaps not be problematic in themselves, participants of this study reported two additional factors that significantly complicate the current picture of faculty work.

First, respondents said that the Bologna Process has placed new demands on their time. They described having to adapt their curricula and syllabi to the new module system, to create new teaching materials, change the grading system, design new tests and handle much more paperwork than before. Commenting on the rising expectations, faculty repeatedly claimed that the implementation process has cost them significant amounts of time and effort.

The core issue, however, is that despite increasing expectations, faculty salaries remain insufficient; by some accounts they are three or four times lower than what they could earn in the private sector. Not surprisingly, this constitutes a source of widespread dissatisfaction. The basic monthly salary 
of a faculty member at this university is about USD 200, with the possibility of additional compensation for seniority and academic rank. The highest salary openly quoted in an interview was USD 600 per month for a department head with the academic degree of Doktor Nauk which is equivalent to the Doktor Habilitatus in the German system.

Participants found it unfair that the heightened expectations they experience are not accompanied by a proportionate decrease in instructional workload or an increase in pay. As two faculty members put it:

Expectations go up, but our salaries stay the same. and

We have European expectations, but Ukrainian funding.

Yet another young faculty member observed:

A cleaning lady in a private company makes as much money as I do. How can that be fair? We are educating the young people on whom our future depends. How they are taught will determine how we will live tomorrow. It's such a pity that not many people understand that.

But the concern went beyond just a question of fairness. One claim common among interviewees was that their basic salary was only enough to live on if they have access to free accommodation, which usually entails living with parents or other family members. Also, many faculty members at the early stages of their career rely on family support to offset their low salaries. Over half the academic staff interviewed felt that their salaries were not sufficient to live on, a view held even more widely among the lower ranks. Indeed, $87 \%$ of lecturers said they found it impossible to live on their university income alone (Table 3). A few young lecturers found that their salaries just covered a month's groceries. One recently promoted and newly married professor observed:

Fifty per cent of the people who work here are young, and we can't afford a home of our own or to get a loan. I have to live with my parents.

Another faculty member claimed:

It would be impossible to live if we didn't have second jobs.

Moonlighting was reported as a common response to inadequate salaries. One administrator estimated that $80 \%$ of all faculty members had recourse to supplemental employment outside the university. This figure was consistent with faculty members' own reports, as $85 \%$ of them listed additional sources of income that they rely on, including second jobs and other types of financial support. These concerns, however, received limited attention from administrators; in fact, only a few empathised with the difficulty faced by faculty. The majority of administrators argued that second jobs contribute to 
Table 3. Perceptions of salary sufficiency by academic rank

\begin{tabular}{lcc}
\hline \multicolumn{1}{l}{ It is impossible to live on my faculty salary: } & \\
\hline Rank & Frequency $(\%)$ & Total number \\
\hline Lecturer & $14(87 \%)$ & 16 \\
Professor & $3(30 \%)$ & 10 \\
Head of Department & $2(33 \%)$ & 6 \\
Administrator & $0(0 \%)$ & 7 \\
Total & $19(49 \%)$ & 39 \\
\hline
\end{tabular}

academic development by exposing faculty to the "real world" outside the walls of the university.

\section{Faculty derive the meaning of their work from teaching but their job security is pegged to research productivity.}

Despite the participants' concern about their teaching load, teaching was a top source of job satisfaction for the majority of respondents. When describing the nature of their work, interviewees talked almost exclusively about their instructional activity; they had to be prompted to talk about their involvement in research. When asked to talk about their job satisfaction, 29 of the 39 respondents talked about their students: the joy of seeing comprehension in their eyes, the challenge of responding to their questions and pride in their accomplishments. Two comments capture the teaching ethos evident in the interviews:

It gives my life meaning to think there are over 1000 professionals in

Ukraine who received some of my heart and instruction.

and

... my students are everything to me.

Interviewees emphasised that the majority of people who work at the university are guided by moral rather than financial motivations. It was apparent throughout interviews that the university is characterised by a strong teaching culture and a collective sense of responsibility for nurturing competent and ethical professionals.

While the faculty members' hearts may be in their teaching, job security depends on other things. Interviewees emphasised that their job security depends more on sustained research output than the quality of their teaching. They consistently observed that the pressure to publish is intensified not just by the absence of tenure, but also by the short duration of faculty contracts. Failure to publish carries the perspective of not having one's contract renewed.

The pressure to produce research was magnified by two factors. First, many of the academic staff were keenly aware of the recent drop in college 
applicants and feared that the university would need to downsize. One administrator explained that the university has faced increasing competition over the last five years, forcing faculty to work harder to look good in rankings. Over $60 \%$ of those interviewed talked about the decrease in student numbers, resulting in some colleagues losing their jobs in recent years. In one department, it had been announced that $40 \%$ of academic staff, amounting to 20 professors, would lose their jobs the following year. The result of the employment squeeze for faculty was summarised by one respondent who said:

The average professor really has to sweat to get his contract prolonged.

Second, for the university to maintain a high level of accreditation, a certain percentage of its academic staff must hold doctoral degrees, and these have a research component. Participants in the study reported that university administration exerted a great deal of pressure on academic staff to obtain further degrees. It was widely recognised that research and publishing, which contribute towards obtaining a degree, are a prerequisite to advancement. Publishing is also interpreted as a signal that a faculty member is seeking to advance his or her academic career.

The strategy adopted by the administration, as expressed by one department head, is to create "green corridors" for people who make progress towards doctoral degrees. The perceptions of faculty, however, were quite different. While they confirmed the existence of strong institutional support for pursuing doctoral degrees, they emphasised the negative aspects of the pressure they experience. These include the constant threat of sanctions for insufficient productivity, pressure from advisors to finish their dissertations as quickly as possible and the utmost difficulty to find the time to do research. Although publishing was seen as basic job insurance, it was an insurance that many found difficult if not impossible to secure. One faculty member claimed:

I can only devote about $20 \%$ of my time to research. I have ideas, but I have other duties that take too much time.

Another complained:

My contract is for one year, and to have it prolonged I need publications. But what kind of research can you do in a year? ... If I submit a paper in November, it is published in April, and to have my contract renewed I need these papers. It's an unhealthy pressure.

Overall, faculty clearly recognised the squeeze they are in. They view their teaching loads as high and their salaries as inadequate. While under great pressure to do more research, their salaries are pegged to their teaching load, not to research productivity. They understand that the way to maintain and increase salary is through more teaching but that heavy teaching loads leave little time for research. 


\section{Faculty are pressured to do more research, but not necessarily good research.}

The interviews revealed a number of institutional strategies for dealing with the multiple pressures affecting faculty, primarily as it relates to research. Respondents explained that the majority of their research is published in Ukrainian or English language journals published by their own or nearby universities, with virtually no international audience. Since these journals have very limited circulation, they generate little or no income from subscription sales and, consequently, levy a page charge on authors that can run as high as USD 20 per page. To help its own faculty succeed in the push for publications, the university subsidises the page cost for those who publish in its own journals. Administrators viewed this arrangement as an incentive to encourage research and as a fringe benefit encouraging the development of its academic staff. However, standards for accepting manuscripts for publication are low and few readers outside the institution see the work once it is published.

The institutional standards of research productivity have the effect of publicly setting the publication bar high, then lowering it by providing low quality, low visibility journals as outlets for scholarly research. As two faculty members noted:

It is not worth doing decent research.

and

Sometimes the research is of good quality, but sometimes very bad. We have a system with points, but you don't get more points if your research is very good.

Some interviewees claimed that the greatest obstacle is not the review process, but the time required and the cost of publication. Around 30\% indicated that they do not believe that research done at their university is good or innovative. While these comments represented a minority opinion, they surfaced often enough to suggest a strong undercurrent of dissatisfaction with how research productivity is evaluated and rewarded. Similar opinions were particularly common among faculty engaged in international projects, who observed that research done at their institution is not as rigorous as in partnering countries. One instructor went so far as to estimate that $95 \%$ of the scientific work done at his institution does not represent much value. Others commented:

It is great form, but there is no content or beneficial application. It's done for looks, just like some students study for the looks of a diploma. and

Support for research is very poor throughout our entire system. 
While crucial to job security, research was not widely cited as a source of job satisfaction. In only a couple of instances did a faculty member's description of their work hold any connotation of knowledge creation. Research productivity was more commonly treated as a symbol of an instructor's personal growth or organisational commitment, not a contribution to the larger society.

\section{Discussion}

The findings of this study portray a university caught in a storm of pressures that pit well-established, widely understood and rather traditional institutional goals and procedures against a set of externally imposed changes and political pressures. The institutional effort to respond to external challenges has led to a series of misalignments and tensions that are reshaping how academic staff approach their careers and day-to-day work at the university.

Despite its well-established status and high level of prestige, the institution resorted to the type of "decoupling" of internal and external activities described by Weaver (2008) in which internal institutional structures and actions are not fully aligned with public statements. What results is a series of mixed messages communicated to the academic staff; consequently, external rhetoric about faculty productivity remains in tension with realistic internal work expectations. Our findings also indicate that mixed messages regarding productivity are a central ingredient of a double bind experienced by academic staff at this university. Much like the institution itself, instructors are unable to resolve the ambiguity surrounding what is actually expected of them. While the university cannot question national priorities if it wants to assure continued institutional funding and legitimacy, faculty are prevented from speaking out for fear of losing their jobs. In the end, both institutional and individual actors are obliged to appear responsive to environmental demands in order to survive (Weaver, 2008).

Where internal and external demands clash with the greatest force is in relation to the role of research. Greater pressure to conduct research, reinforced by numerous environmental forces, conflicts with the professional motivations of the majority of faculty, the existing structure of faculty remuneration and the necessity to seek supplemental employment. Increased research output is an extrinsic goal necessitated by the demands of the environment, but is not necessarily consistent with the informal structure of faculty motivations and daily activities. This comes as no surprise given that the structure and culture of universities in Ukraine remain strongly influenced by the Soviet model of higher education, in which universities are oriented towards teaching and research is left to special scientific institutes (Péteri, 
2000). After so many years of an exclusive focus on teaching, it is unreasonable to expect academics to quickly embrace research in the same way their colleagues do in the West. The coping strategies of faculty in this study mirror the institutional response: they separate talk from action when it comes to research. Second, the tasks that actually get accomplished tend to reflect the institution's traditional role of instruction.

Most other universities in Ukraine are far less fortunate and less powerful than this flagship institution. They are even more susceptible to the change in governmental agendas, enrolment fluctuations and financial cuts. Their coping strategies are similar to those described above, but probably even more pronounced as the government strives to subscribe to the Bologna Process across its higher education system. While the government and universities expected a transitional period of difficult adjustments, they did not fully anticipate how other external economic and demographic forces would interact with internal changes. Our findings suggest that the transition required for universities to comply with the Bologna Process is often at odds with the traditional role Ukrainian academic staff have typically played within their workplace. At the same time, many universities are facing declining enrolments that translate directly into budget cuts. Universities will struggle to appear responsive to the government's call for reform if they lack the incentives they need to keep academic staff motivated and engaged.

\section{Conclusions}

One can criticise the university described in this study for falling into what some might see as a type of hypocrisy, where public statements differ from actual organisational practice (Weaver, 2008), or one can laud its efforts as an adaptive organisational response to contradictory demands. Both responses are justified. Although the systemic inconsistencies have a taxing impact on individual faculty members, they provide an institutional safety valve that allows reform to appear to move forward even as its effects are buffered by less visible actions aimed at stretching resources and modifying expectations.

What seems clear, however, is that the cost of reform falls on individual faculty members and the contradictions of the Ukrainian system of higher education converge in their day-to-day work. The findings of this study suggest that the rhetoric of change may be moving faster than the reality. Such rhetoric, however, comes at a price. Its real cost is measured by the fiscal and psychological strain placed on faculty. For them to appear responsive to such numerous and competing pressures requires a significant investment of their time and resources, but it is an investment that does not bring the same long-term payoff as actual reform. Since academic staff act as gatekeepers of 
educational change, their disillusionment with partial and underfunded reform threatens to slow down and possibly undermine the national effort to modernise the higher education system, a point corroborated by Varghese (2004).

Our findings regarding the responses of universities and individual academic staff to externally imposed change are relevant in a growing number of contexts. Efforts toward cross-national harmonisation of higher education systems through the introduction of Bologna-type reforms are being undertaken in Asia, Africa and Latin America (Zgaga, 2006). Around the world, the emergence of the "knowledge economy" has cast knowledge creation as the new dominant rationale for the existence of the university. Systems traditionally oriented towards teaching are facing new pressures, but often their structures are not sufficiently aligned to support high-quality research (Melguizo and Strober, 2007).

As expectations of academic staff change, successful institutional adaptation will depend on an appropriate shift in incentive systems and ongoing faculty development to reduce the complexity of academic work in a changing environment. This study illustrates the pitfalls of increasing demands on faculty without a shift in incentives or sufficient faculty development efforts. Without systemic support, new demands on academic staff will likely clash with traditional incentive structures, producing substandard outcomes while threatening to erode the motivations that led many individuals into the academic profession.

Our findings suggest that in the presence of environmental pressures, a reform that shifts its main costs to faculty without adjusting the institutional support structure will likely elicit counterproductive coping strategies. Underfunded reform runs the risk of creating little more than an appearance of change at the expense of energies that could otherwise be spent much more productively. Higher education leaders would be well advised to give careful attention to the institutional-level dynamics that may accompany such change. 
The authors:

Marta A. Shaw (corresponding author)

Jandris Scholar

Jandris Center for Innovative Higher Education

University of Minnesota

330 Wulling Hall

86 Pleasant Street SE

Minneapolis, MN 55455

United States

E-mail: martashaw@umn.edu

David W. Chapman

Birkmaier Professor of Educational Leadership

University of Minnesota

330 Wulling Hall

86 Pleasant Street SE

Minneapolis, MN 55455

United States

E-mail: chapm026@umn.edu

Nataliya L. Rumyantseva

Lecturer in Higher Education Studies

University of Southampton Building 32, University Road

Southampton, S017 1BJ

United Kingdom

E-mail: n.rumyantseva@soton.ac.uk

The funding source supporting the research presented was the University of Minnesota and the University of Southampton.

\section{Notes}

1. The terms "faculty" and "academic staff" are used interchangeably to indicate those individuals employed by higher education institutions to deliver instruction and conduct research.

2. To mask the identity of the participating university, the full citation has been withheld. 


\section{References}

Anon (2009), full citation withheld to protect the anonymity of the university that was the focus of this study.

Argyris, C. and D. Schön (1978), Organizational Learning: A Theory of Action Perspective, Addison-Wesley, Reading, MA.

Bateson, G. (1972), Steps to an Ecology of Mind, Ballantine Books, New York.

Brunsson, N. (1989), The Organization of Hypocrisy: Talk, Decisions, and Actions in Organizations, Wiley and Sons, New York.

Clement, M., L. McAlpine and K. Waeytens (2004), "Fascinating Bologna: Impact on the Nature and Approach of Academic Development", International Journal for Academic Development, Vol. 9, No. 2, pp. 127-131.

Chapman, D.W. (2009), Teacher Motivation: Incentives and Working Conditions, Policy Brief No. 9, Secondary Teachers in Southeast Asia Project, World Bank, Washington, DC.

Chapman, D.W., T. Al-Barwani and H. Ameen (2009), "Expanding Post-secondary Access in Oman, and Paying for It", in Jane Knight (ed.), Financing Access and Equity in Higher Education, SENSE Publishing, Rotterdam.

Chapman, D.W. and A.E. Austin (eds.) (2002), Higher Education in the Developing World, Greenwood Publishers, Westport, Connecticut.

Kremen, V. and S. Nikolajenko (2006), Higher Education in Ukraine, UNESCO-CEPES Monographs on Higher Education, Bucharest.

Kovtun, O. and S. Stick (2009), "Ukraine and the Bologna Process: A Case Study of the Impact of the Bologna Process on Ukrainian State Institutions", Higher Education in Europe, Vol. 34, No. 1, pp. 91-103.

Lutyński, J. (1990), "System dogmatycznego autorytaryzmu i jego tendencje rozwojowe, ze szczególnym uwzgl?dnieniem roli działa? pozornych i ukrytych" (The System of Dogmatic Authoritarianism and its Developmental Tendencies, with Special Emphasis on the Role of Fake and Hidden Activities), in J. Lutyński (ed.), Nauka i polskie problemy. Komentarz socjologa (Science and Polish Problems. A Sociologist's Commentary), PIW, Warsaw.

Marga, A. (1997), Reforming the Postcommunist University, Journal of Democracy, Vol. 8, No. 2, pp. 159-167.

Melguizo, T. and M.H. Strober (2007), "Faculty Salaries and the Maximization of Prestige", Research in Higher Education, Vol. 48, No. 6, pp. 633-668.

Meyer, J.W. and B. Rowan (1977), "Institutionalized Organizations: Formal Structure as Myth and Ceremony", American Journal of Sociology, Vol. 83, No. 2, pp. 340-363.

Péteri, G. (2000), "On the Legacy of State Socialism in Academia", in M. David-Fox and G. Péteri (eds.), Academia in Upheaval: Origins, Transfers, and Transformations of the Communist Academic Regime in Russia and East Central Europe, Bergin and Garvey, Westport, CT, pp. 275-302.

Pfeffer, J. and G. Salancik (1978), "The External Control of Organizations: A Resource Dependence Perspective”, in J. M. Shafritz, J.S. Ott and Y.S. Jang (eds.), Classics of Organization Theory, Thomson Wadsworth, Belmont, CA, 6th ed., pp. 521-532.

Salmi, J. (2009), The Challenge of Establishing World-Class Universities, the World Bank, Washington, DC.

Savage, C.M. (1990), Fifth Generation Management, Digital Press, Woburn, MA. 
Scott, P. (2009), "Reflections on the Reform of Higher Education in Central and Eastern Europe", in Malcolm Tight (ed.), The Routledge International Handbook of Higher Education, Routledge, New York.

Sztompka, P. (2005), The Sociology of Social Change, Blackwell, Oxford.

Tyszka, K. (2009), "Homo Sovieticus Two Decades Later", Polish Sociological Review, Vol. 4, No. 168, pp. 507-522.

Ukrainian parliament (Verkhovna Rada) (2002), Law of Ukraine No. 2984-III, On Higher Education.

UNESCO Institute of Statistics (2010a), Data Centre: Enrollment in total tertiary, public and private, full and part time, http://stats.uis.unesco.org, accessed 20 February 2011.

UNESCO Institute of Statistics (2010b), Data Centre: Gross enrollment ratio, ISCED 5 and 6, http://stats.uis.unesco.org, accessed 20 February 2011.

UNESCO Institute of Statistics (2010c), Data Centre: Students in tertiary education per 100,000 inhabitants, http://stats. uis.unesco.org, accessed 20 February 2011.

Varghese, N.V. (2004), "Incentives and Institutional Change in Higher Education", Higher Education Management and Policy, Vol. 16, No. 1, pp. 27-39, OECD Publishing.

Weaver, C. (2008), Hypocrisy Trap: The World Bank and the Poverty of Reform, Princeton University Press, Princeton.

Zgaga, P. (2006), On the "External Dimension" of the Bologna Process, Working Group on the External Dimension of the Bologna Process, Oslo, Norway. 